\title{
Comparison of conventional SFRA with intelligent SFRA
}

\author{
Richa Kapoor $^{1^{*}}$ and Himanshu Vijay ${ }^{2}$ \\ PhD Scholar, Dr K N Modi University, Niwai, Rajasthan, India ${ }^{1}$ \\ Professor, Anand Engineering College, Agra, Uttar Pradesh, India ${ }^{2}$
}

(C2017 ACCENTS

\begin{abstract}
Dielectric protection of a transformer bushing crumbles as an element of temperature, oxidation, and dampness. This causes quickened maturing of oil and cellulosic strong protection, producing flaw gasses inside bushing oil and thus permanent failure. To counteract such disappointments, viable examinations and findings should be researched. Dissolved gas analysis (DGA) can give the sign of inner variations from the norm inside the transformer bushing. Also, frequency response analysis (FRA) is a generally acknowledged apparatus for mechanical disfigurement analysis inside power transformers. In spite of the fact that a substantial number of studies have been led on the identification of transformer twisting distortion by FRA method, the effect of bushing deficiencies on the transformer FRA signature has not been adequately examined. The objective of this paper is to propose exact intelligent method and additionally handy investigations showing the effect of bushing issues on the FRA signature.
\end{abstract}

\section{Keywords}

SFRA, Intelligent SFRA, DGA, Power transformer.

\section{Introduction}

The high voltage Power transformers are generally utilized as a part of electric framework and, Due to their confused development, it turns out to be exceptionally hard to repair or supplant the transformer promptly after any failure. The failure might be because of many reasons like lightning strikes, exchanging places, link strikes, mechanical assembly disappointments and different mishaps in their life expectancy. Thus, of these, many failures can happen in power transformer like mechanical abnormalities, twisting and harms in the dynamic piece of transformer which is centre and winding [1]. So, genuine consideration is to be given to keep away from different mechanical or warm weakening in power transformer because of short circuit. New Transformer can survive various short-circuits amid its life, however after a span of time their life does deteriorate. There is some slight winding development happen, and its capacity to survive additionally short-circuits will be lessens. To keep a harm phase of transformers, diverse sorts of the estimations test perform on transformer which portrays the real condition of transformer.

\footnotetext{
*Author for correspondence
}

\section{Sweep frequency response analysis}

A Power transformer can be assumed as combination of electrical components, for example, inductances, capacitances and resistances. When it is energized by the input signal, creates an electric output which is reliant on the input signal. This response is termed as Transfer Function TF. The estimations of RLC components rely on upon the geometry and materials of each piece of the transformer, windings, centre, tap changer, tank, and so forth. Any change, for example, relocation or harm of a given component, causes a noteworthy change in the proportion amongst output and input [2].

Conventional methods like dissolved gas in oil analysis (DGA), were used earlier. DGA is used to get estimate of the percentages of composite gases in insulating oil, and interpret the type of fault in power transformer according to the composition of gases. However, DGA is not capable of recognising precise electrical and mechanical faults. Other electrical diagnostic tests like winding resistance test, short circuit impedance, oil Analysis and sweep frequency response analysis (SFRA) are also used for identification of abnormalities in the core and winding geometries of power transformer [3].

SFRA analyzes a deliberate amount and reference information, and in this way creates greatness and 
stage reactions in recurrence spaces. Subsequent to getting the aftereffect of correlation if any deviation is discovered, disintegration can be anticipated. The yields are the two parameters; Impedance and Phase as appeared in Figure 1. SFRA can even identify the smallest change in winding development of power transformer. It fundamentally measures the impedance of transformer winding over an extensive variety of frequencies. It can identify a abnormalities of winding and its developments or an incomplete breakdown of winding, a short-circuited turn or opened winding, a loose and a harmed switching system, a core association issue and a center movement or its wrong grounding.

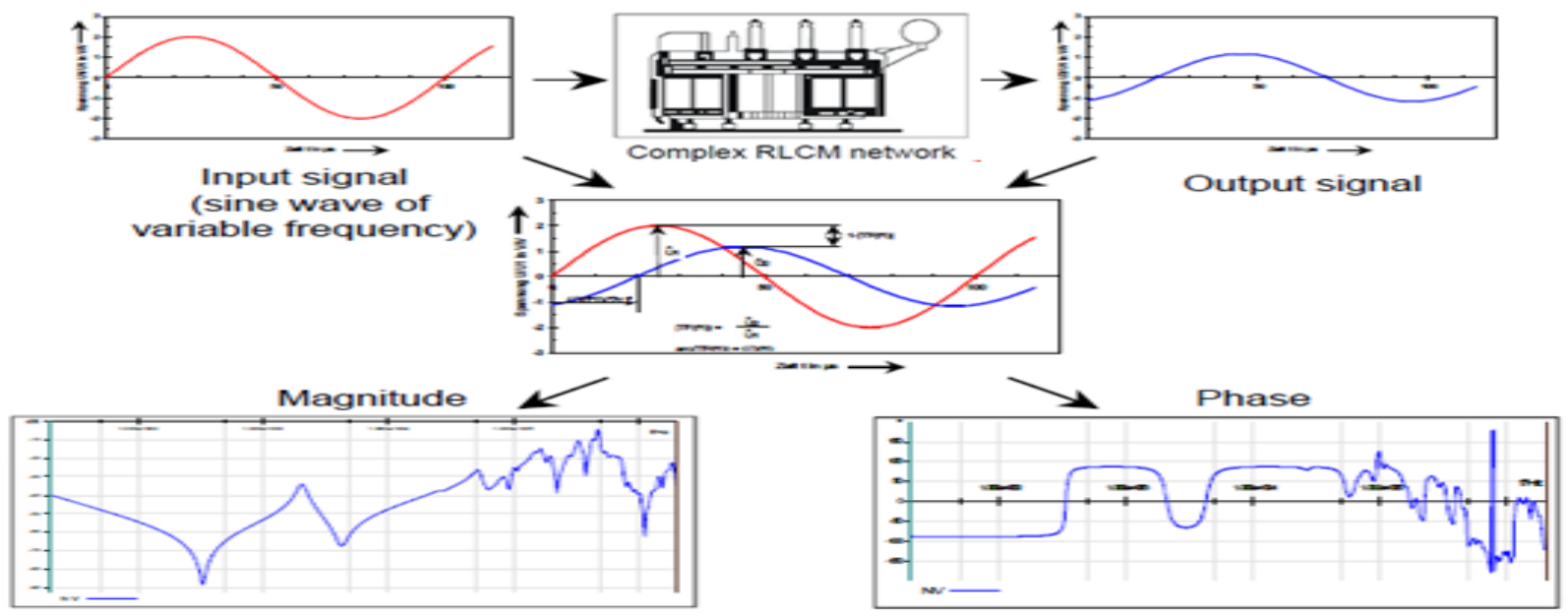

Figure 1 Principle of SFRA

SFRA test is utilized after the disappointment of transformer which includes interior assessment and destroying of transformer [4]. When contrasted with other symptomatic strategies, SFRA system gives the extensive variety of dependable data about the mechanical status of a transformer's dynamic part.

Faults, which can change either the winding capacitance or the winding inductance, are distinguishable. It permits location of most conceivable methods of winding distortion, for example, radial, axial, twisting and as well as changes in the clamping pressure [5].

In regular strategy result translation of SFRA test comes about for power transformer prompting the conclusion of fault relies on the experience of human specialists. Because of this a high level of irregularity and equivocalness have been watched with respect to understanding of result by various human specialists, so there is a need to create insightful framework for SFRA. In this paper master framework programming has been produced utilizing reasonable MATLAB code. It has been effectively connected to different transformers.

\section{Measurement method}

A SFRA response is portrayed with reference to the parameters of the proportionate circuit outline of a power transformer. At low frequencies, ordinarily in the vicinity of $20 \mathrm{~Hz}$ and $1 \mathrm{kHz}$ (recurrence reaches are relying upon the transformer to be tried) the charging inductance overwhelms the reaction. The primary parallel resonance recurrence is because of the resonance between the polarizing inductance of the iron center and the parallel, individually parasitic capacitance of the power transformer [6].

At medium frequencies, commonly in the vicinity of $1 \mathrm{kHz}$ and $10 \mathrm{kHz}$, the parallel capacitance and the shared inductances are dominating the response. The common inductances are because of the shared coupling impact between the high voltage (HV) and low voltage (LV) winding of a power transformer. Thus, this frequency range is frequently eluded to as the common coupling frequency extend.

At high frequencies, regularly in the vicinity of 10 $\mathrm{kHz}$ and $1 \mathrm{MHz}$, the response is ruled by the winding capacitances and inductances. Any mechanical change inside the winding structure would influence this frequency range. 
At frequencies of $1 \mathrm{MHz}$ and past, the impact of the real estimation setup will have an awesome effect the reaction. Thusly, it is not standard practice to break down follows at frequencies past $1 \mathrm{MHz}$ [7]. The upper recurrence confine for dissecting purposes depends particularly on the physical size of the power transformer and is lower the greater the transformer. Typically, for a large power transformer (>500MVA,
$>400 \mathrm{kV}$ ) the upper frequency limit is approx. $0.5 \mathrm{MHz}$. For a small distribution transformers (<5MVA) the upper frequency limit is approx. $4 \mathrm{MHz}$ ) [8]. Figure 2 shows simplified network behavior of a transformer's active part.

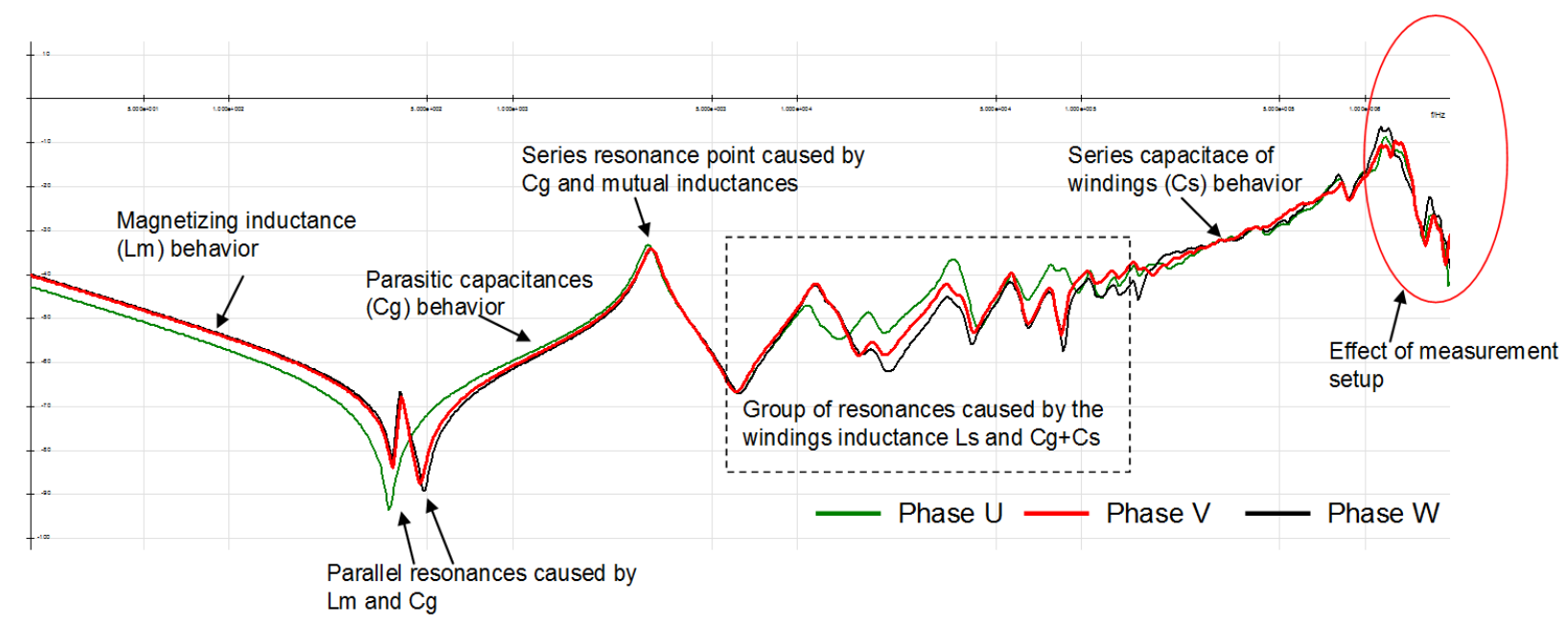

Figure 2 Simplified network behavior of a transformer's active part

\section{Intelligent system of SFRA \\ Case 1: Analysis Using Intelligent System on Transformer B}

\subsection{Test on HV Open LV}

Investigation was performed by utilizing intelligent system on transformer. It was test on HV open LV for phase to phase examination strategy. Examination
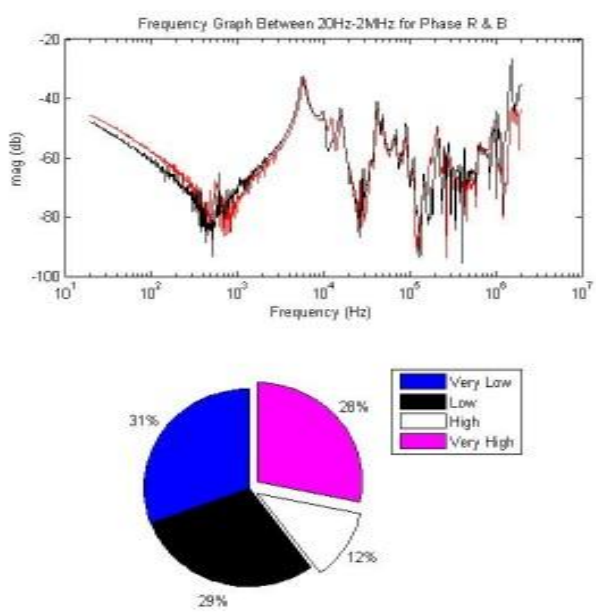

Figure 3 Phase R \& B (frequency band $20 \mathrm{~Hz}-2 \mathrm{MHz}$ ) was done in frequency band between $20 \mathrm{~Hz}$ to $2 \mathrm{MHz}$ and fault was distinguished amid typical investigation. Their outcome is given in Figure 3 and 4 individually with frequency diagram, phase graph and pie graph with general rate level of fault for each stage. The transformer is probably going to have axial shift and movement of tap winding.

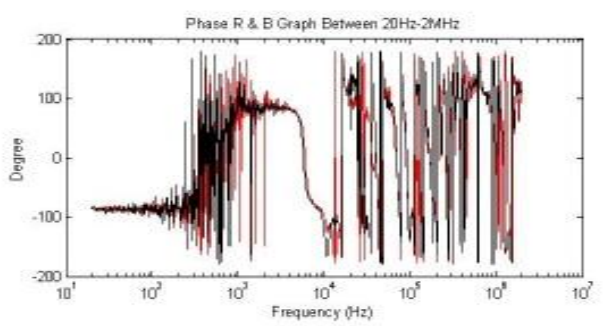



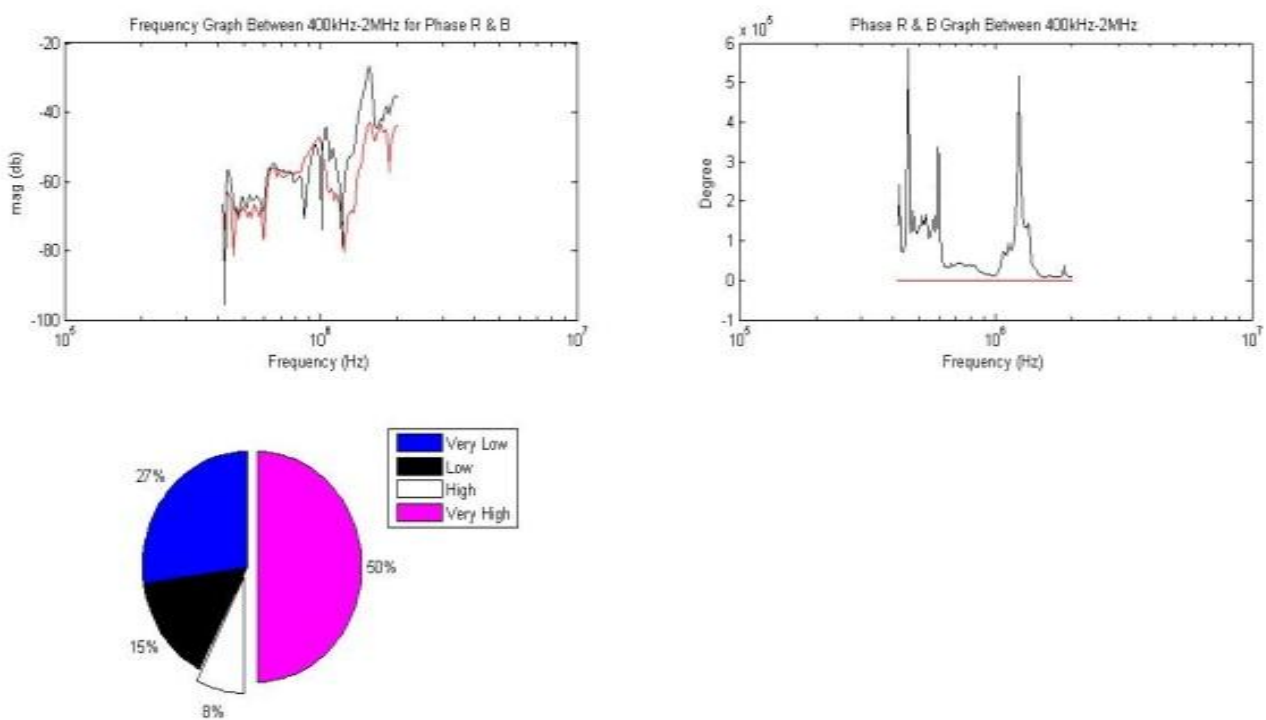

Figure 4 Phase R \& B (frequency band $400 \mathrm{KHz}-2 \mathrm{MHz}$ )

\subsection{Test on HV Short LV}

Investigation was performed by utilizing intelligent system on transformer. It was test on HV short LV for phase to phase correlation strategy. Investigation was done in frequency band between $20 \mathrm{~Hz}$ to $2 \mathrm{MHz}$
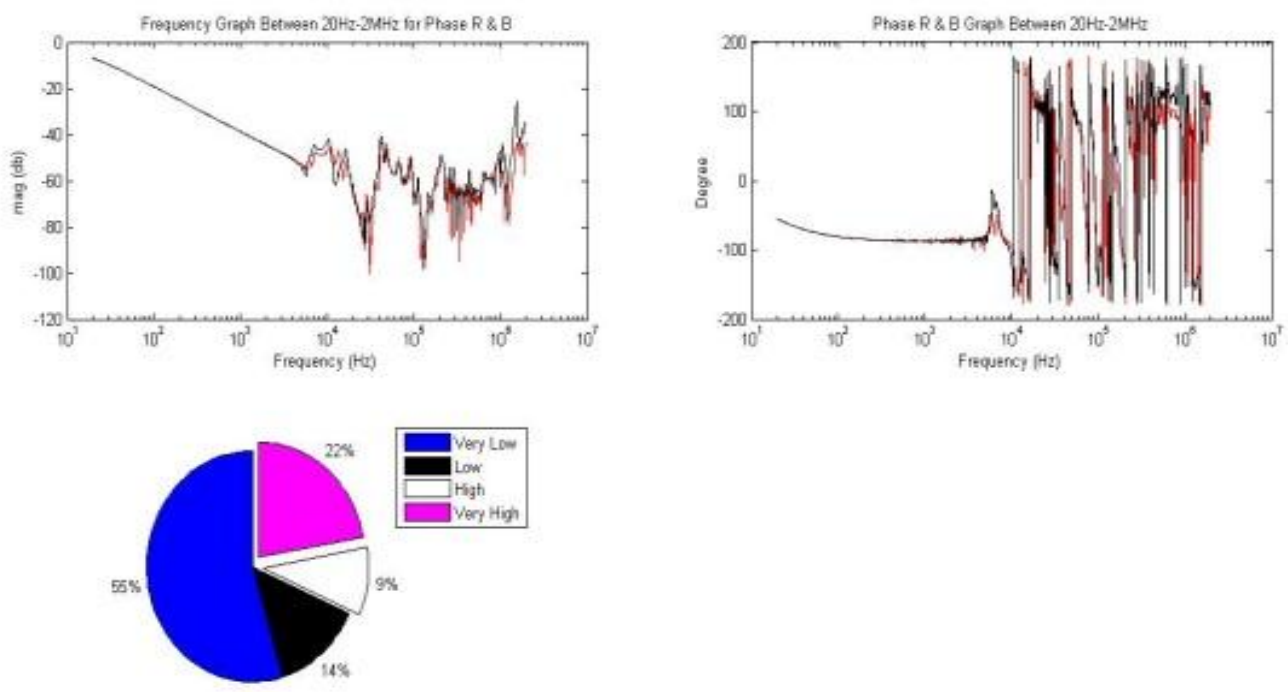

and fault was recognized amid typical examination and their outcome given in Figure 5 separately with frequency diagram. Phase diagram and pie outline with general rate level of fault for each stage. The transformer is probably going to have axial and shift development of fundamental tap winding leads.

Figure 5 Phase R \& B (frequency band $20 \mathrm{~Hz}-2 \mathrm{MHz}$ )

\subsection{Test on LV Open HV}

Presently investigation was done in frequency band $20 \mathrm{~Hz}-2 \mathrm{MHz}$ for normal user fault was distinguished in this frequency band and their outcomes are given

in Figure 6, 7 and 8. Individually with frequency diagram, phase graph and pie graph with rate level of fault for each stage. The transformer is probably going to have mass winding displacement, bracing 
Richa Kapoor et al.

structure issue, misshaping in ma winding, axial displacement.
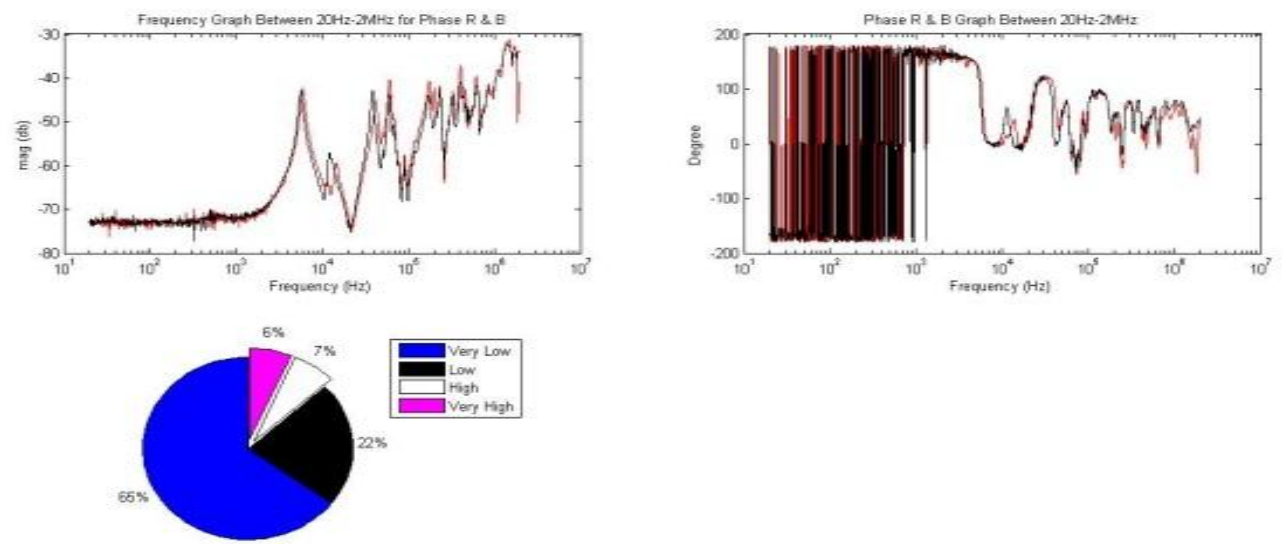

Figure 6 Phase R \& B (frequency band $20 \mathrm{~Hz}-2 \mathrm{MHz}$ )
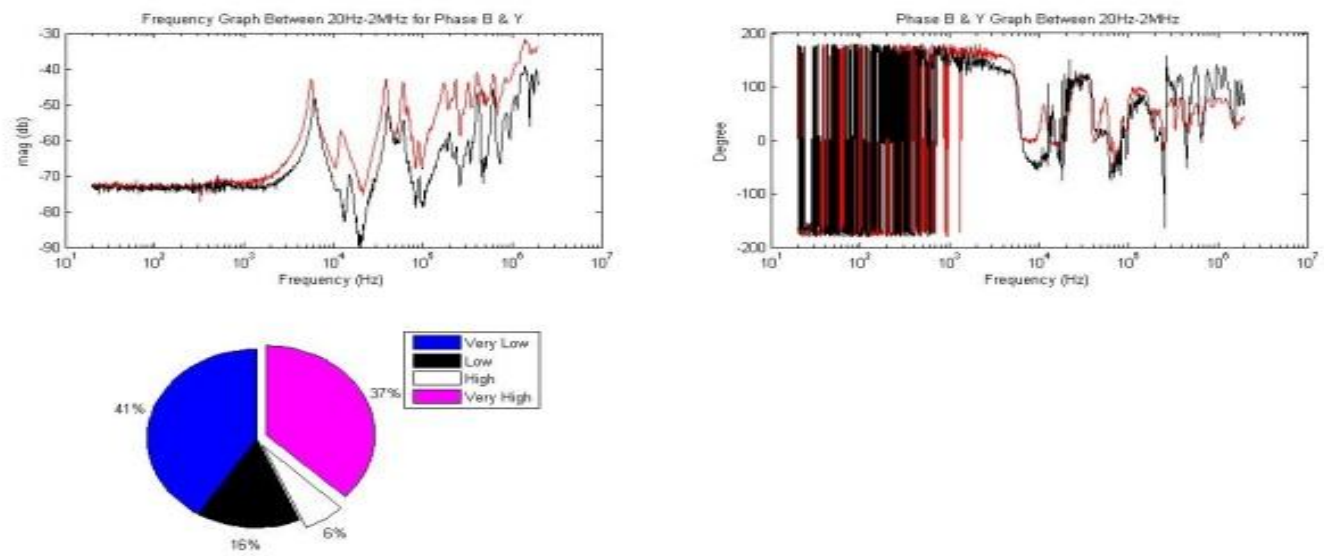

Figure 7 Phase B \& Y (frequency band $20 \mathrm{~Hz}-2 \mathrm{MHz}$ )
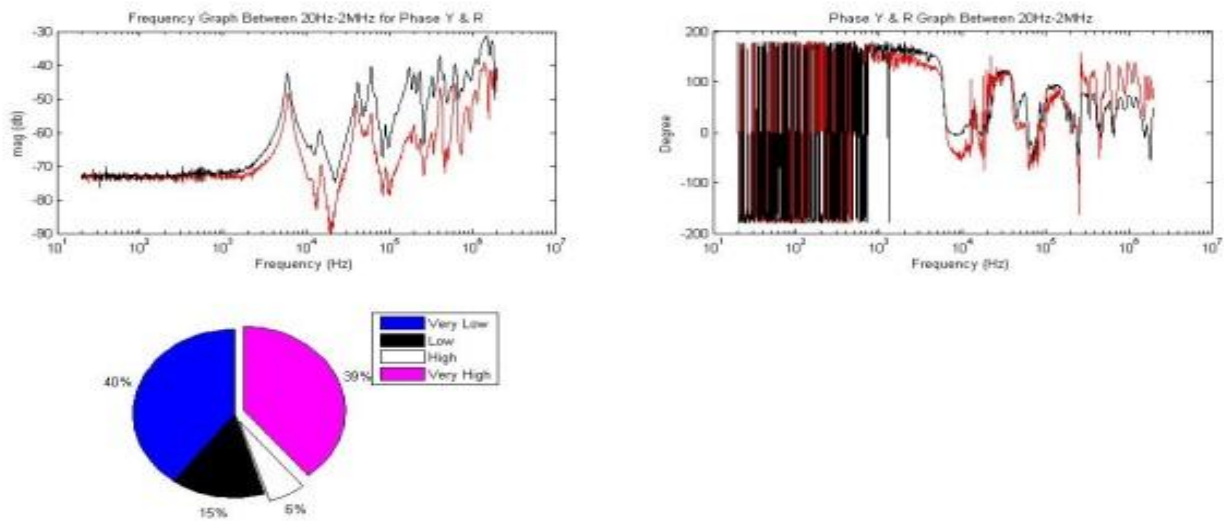

Figure 8 Phase Y \& R (frequency band $20 \mathrm{~Hz}-2 \mathrm{MHz}$ ) 86 


\section{Discussion}

It can be seen from the above results that in the conventional method of prediction of results of SFRA for power transformer the expertise and experience of human being is used. It is not very user friendly. It will only be predicted by the experts. But in the case of intelligent system the prediction of healthy and non-healthy condition of transformer can be done by the system and thus the prediction is also done by the same.

\section{Conclusion and future scope}

Results have been obtained for transformers by SFRA test set up. The output of the setup is magnitude and phase response. In the conventional method, the response is studied by some expert and thus the interpretation is given. But in the intelligent system developed in MATLAB the system will analyse and predict the fault in the transformer and result will be displayed with the percentage probability of fault.

Further, in future artificial neural network and fuzzy logic can be implemented for advancement in this method of SFRA.

\section{Acknowledgment}

None.

\section{Conflicts of interest}

The authors have no conflicts of interest to declare.

\section{References}

[1] Singh J, Sood YR, Jarial RK. Novel method for detection of transformer winding faults using sweep frequency response analysis. In power engineering society general meeting 2007 (pp. 1-9). IEEE.

[2] Koley C, Purkait P, Chakravorti S. Time-frequency representation of resistance for modeling of transformer winding under impulse test. IEEE Transactions on Power Delivery. 2006; 21(3):1367-74.

[3] Secue J, Mombello E. New methodology for diagnosing faults in power transformer windings through the sweep frequency response analysis (SFRA). In transmission and distribution conference and exposition: Latin America 2008 (pp. 1-10). IEEE.
[4] Fuhr J. Benefits and limits of advanced methods used for transformer diagnostics. In electrical insulation conference 2009 (pp. 262-72). IEEE.

[5] Ryder SA. Diagnosing transformer faults using frequency response analysis. IEEE Electrical Insulation Magazine. 2003; 19(2):16-22.

[6] González C, Pleite J, Salas RA, Vázquez J. Transformer diagnosis approach using frequency response analysis method. In IEEE annual conference on industrial electronics 2006 (pp. 2465-70). IEEE.

[7] Kraetge A, Kruger M, Velasquez JL, Viljoen M, Dierks A. Aspects of the practical application of sweep frequency response analysis (SFRA) on power Transformers. In 6th southern Africa regional conference, CIGRE 2009 (p. 504).

[8] Wang M, Vandermaar AJ, Srivastava KD. Transformer winding movement monitoring in service-key factors affecting FRA measurements. IEEE Electrical Insulation Magazine. 2004; 20(5):512.

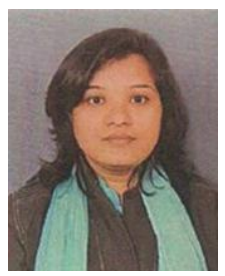

Richa Kapoor has done her M.Tech from Uttar Pradesh Technical University, Lucknow, India in 2011. She did her B.Tech in 2002 in Electrical and Electronics from BLDEA College, Bijapur, India. She is pursuing $\mathrm{PhD}$ in Power system. The author's major field of study is soft computing in power system. Currently she is working as Assistant Professor in HCST, Mathura India in Electrical and Electronics Department. She is a member of ISTE. She has presented many paper in National and international conferences held in India.

Email: richakapoor11@gmail.com

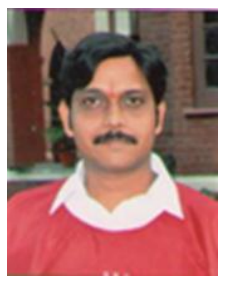

Dr. Himanshu Vijay had been awarded his Ph.D Degree (Electrical Engineering), in 2011 from Faculty Engineering D.E.I. Dayalbag Agra, after dully completing his M.Tech (Power System, 1997) \& B.Sc. Engineering (Electrical Engineering, 1995 from the same institute. He has about 18 Years of teaching experience in various Engineering colleges. Currently he is working as Head of Department (Electrical and Electronics Engineering) in Anand Engineering College, Agra, and his area of interests are Power Systems \& Electrical Machine. He has written many research papers in various fields. 